\title{
Simultaneous determination of sibutramine and its derivatives in weight loss dietary supplements by LC-MS/MS
}

\author{
Duong Thi Mai Hoa ${ }^{1,2 *}$, Pham Thi Ngoc Mai ${ }^{2}$, Hoang Quoc Anh ${ }^{2}$, Cao Cong Khanh ${ }^{1}$ \\ Nguyen Thi Hong Ngoc ${ }^{1}$, Mac Thi Thanh Hoa ${ }^{1}$, Tran Hung Son ${ }^{1}$ \\ Nguyen Thi Van Anh ${ }^{3}$, Le Thi Hong Hao ${ }^{1,2}$ \\ ${ }^{1}$ National Institute for Food Control, Hanoi \\ ${ }^{2}$ University of Science, Vietnam National University, Hanoi \\ ${ }^{3}$ Viet Nam University of Traditional Medicine, Hanoi
}

(Received: 27/3/2020; Accepted: 19/6/2020)

\section{Abstract}

The liquid chromatography tandem mass spectrometry method (LC-MS/MS) was used to determine the content of sibutramine (SB), N-desmethyl sibutramine (DSB) and N-didesmethyl sibutramine (DDSB) illegally mixed in weight loss dietary supplements. Sibutramine and its derivatives were extracted by methanol; impurities in the extract were removed by graphitized carbon black (GCB) adsorbent. The chromatographic separation of analytes took place on C18 column $(100 \mathrm{~mm} \times 2.1 \mathrm{~mm}, 3.5 \mu \mathrm{m})$ with a gradient mobile phase of acetonitrile and $2 \mathrm{mM}$ ammonium acetate in $0.1 \%$ formic acid solution. Multiple reaction monitoring (MRM) in the positive mode was used to detect and quantify SB, DSB and DDSB at $\mathrm{m} / \mathrm{z} 279.9 / 124.8$; 266.0/124.8 and 252.1/125.0, respectively. The method was validated following the AOAC requirements for specificity, repeatability and recovery. Calibration curves lineared from 0.002 to $0.1 \mu \mathrm{g} / \mathrm{mL}$ for SB, DSB and DDSB. The method was successfully applied to determine the content of SB, DSB and DDSB in weight loss dietary supplements that were randomly collected from phamacies in Hanoi of three formulations of hard capsule, soft capsule and teabag. The results shown that six samples had SB and DSB with the content in the range of $0.817-31.7 \mathrm{mg} / \mathrm{g}$.

Keywords: sibutramine, $N$-desmethyl sibutramine, $N$-didesmethyl sibutramine, weight lossdietary supplement, LC-MS/MS.

\section{INTRODUCTION}

Sibutramine (SB) acts by inhibiting the re-uptake of neurotransmitter serotonin, norepinephrine and dopamine and enhancing satiety. Consequently, it prevents compulsive eating and inhibits the sensation of hunger in obese patients [1-4]. After being administered to animals and humans, sibutramine is rapidly metabolized to N-mono-desmethyl sibutramine (DSB) and $\mathrm{N}$-didesmethyl sibutramine (DDSB) [5-6]. The in vivo effects of sibutramine are mainly due to the actions of these two metabolites $[4,7,8]$. Undersirable effects of SB are excessive stimulation of the central nervous system, some side effects such as restlessness, dry mouth, headache, paralysis, paresthesias [9]. Furthermore, it is linked to cardiovascular risk such as increased blood pressure, heart rate and stroke risk [10].

Sibutramine is one of the most popular anesthetic drugs found in herbal based weight loss foods. However, SB has been banned from circulating on the European market since January 21, 2010 due to side effects [11]. In Viet Nam, SB containing products have been withdrawn

\footnotetext{
${ }^{*}$ Corresponding author: Tel 0974554568

Email:hoamaistudy@yahoo.com
} 
from circulation registration numbers since April 2011. Dietary supplements for weight control should be safe without causing any danger to health. However, illegal dealers add some drugs such as sibutramine's analogs including N-desmethyl sibutramine and N-didesmethyl sibutramine into the dietary supplements to enhance the weight-reducing effect of the products. The presence of SB and its derivatives in dietary supplements for weight control caused serious health problems for consumers [5].

Recently, there have been a number of analytical methods to determine the illegally mixed drugs in herbal supplements such as infrared spectrometry (IR), raman spectroscopy, high performance liquid chromatography (HPLC) - diode array detection (DAD) [12], etc. Sabina Strano and his colleagues developed the method to detect the metabolites of sibutramine in urine by GC-MS [13], all SB' metabolites were clearly detectable in a range of concentrations between 10 and $50 \mathrm{ng} / \mathrm{mL}$, satisfying the minimum required performance limits of the world Anti - Doping Agency [14]. Sibutramine and its two metabolites and one analogue in an herbal product for weight loss were detected by liquid chromatography triple quadrupole mass spectrometry and time of flight mass spectrometry by Zou P and his colleagues [15]. It is important for health authorities and health professionals to detect and identify synthetic drugs and their analogues in slimming products [15]. Venkata developed a method to quantify sibutramine and its two metabolites in human plasma by LC-ESI-MS/MS, the method was applied in a bioequivalence and pharmacokinetic study [4].

In Vietnam, the HPLC method to determine the content of sibutramine in dietary supplement for weight control was validated [16]. However, there has not been any studies on the simultaneous determination of the content of SB and its derivatives yet. Therefore, the goal of this research was to develop a method to simultaneously determine the content of SB and its derivatives. LC-MS/MS was chosen as an analytical method, the method after being validated will be applied to control the SB, DSB and DDSB illegally mixed in weight loss dietary supplement.

\section{MATERIALS AND METHODS}

\subsection{Materials}

The common formulation of weight loss dietary supplements are hard capsules, soft capsules and teabags, which were randomly collected from pharmacies in Hanoi.

\subsection{Standards and Reagents}

Sibutramine hydrochloride, N-desmethyl sibutramine and N-didesmethyl sibutramine were purchased from Sigma Aldrich (purities $\geq 99 \%$ ). HPLC grade methanol $(\mathrm{MeOH})$, acetonitrile $(\mathrm{ACN})$, ethanol $(\mathrm{EtOH})$, acetone, formic acid, hydroxide ammonium $\left(\mathrm{NH}_{4} \mathrm{OH}\right)$ were obtained from Merck (Germany). Ammonium formate, Ammonium acetate of analytical reagent grade were obtained from Merck (Germany). Solid-phase extraction (SPE) strong cation exchange (SCX) cartridge was purchased from Waters. Graphitized Carbon Black (GCB) adsorbent from Agilent, US was used for cleaning impurities in this study.

\subsection{Instrumentation}

Shimadzu's LC20AD high performance liquid chromatography system coupled with the 5500 QQQ (triplequad mass spectrometer of AB-SCIEX, USA) was used in this method. SB,

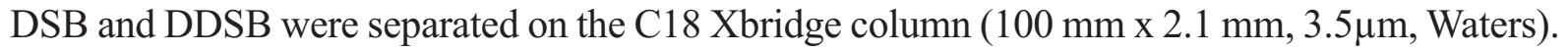
The gradient elution contains Acetonitril (A) and $0.1 \%$ formic acid in $2 \mathrm{mM}$ ammonium acetate 
(B). The injection volume was $10 \mu \mathrm{L}$. The sample was introduced into ESI source at a flow rate of $0.4 \mathrm{~mL} / \mathrm{min}$ to enable the targeted qualitative determination of SB, DSB and DDSB.

\subsection{Methods}

\subsubsection{Mass spectrometry optimization}

Using flow injection analysis (FIA) to directly inject the $10 \mathrm{ng} / \mathrm{mL}$ mixed standard solution of sibutramine, $\mathrm{N}$-desmethyl sibutramine and $\mathrm{N}$-didesmethyl sibutramine into mass spectrometry without liquid chromatographic separation. Electrospray ionization (ESI) technology in positive mode was selected to investigate the precursor and product ion. Based on the signal of analyte on the chromatogram to select the optimal parameters for MS and MS/MS analysis.

\subsubsection{Sample prepration}

\subsubsection{Investigation of extraction solvent}

Four extraction solvents including (1) $\mathrm{MeOH}$, (2) $\mathrm{ACN}$, (3) EtOH and (4) acetone were investigated for the extraction of SB, DSB and DDSB from spiked samples. After adding the extraction solvent, the sample was sonicated for 20 minutes, followed by centrifugation at 4.000 rpm for 10 minutes. Sample was then diluted with appropriate ratio before being injected into LC-MS/MS.

\subsubsection{Investigation of cleanup step}

It is always necessary to remove impurities in the matrix of the samples to reduce interferents and protect the LC-MS/MS system. The samples were cleaned by 3 procedures as in Table 1 . The most effective cleaning technique was chosen based on the recovery of spiked samples.

Table 1. Procedures of sample cleaning

\begin{tabular}{lll}
\hline \multicolumn{1}{c}{ Procedure 1 } & \multicolumn{1}{c}{ Procedure 2 } & \multicolumn{1}{c}{ Procedure 3 } \\
\hline & - Filter extraction solution. & - Filter extraction solution. \\
& - Activate the column: $6 \mathrm{~mL}$ & - Pipette $15 \mathrm{~mL}$ of extraction into \\
& $\mathrm{MeOH}, 6 \mathrm{~mL} \mathrm{H}_{2} \mathrm{O}$. & centrifuge tube containing $25 \mathrm{mg}$ \\
Filter immediately & - Transfer samples on column: & GCB. \\
through $0.25 \mu \mathrm{m}$ & $4 \mathrm{~mL}$ extraction. & - Shake about 30 - 60 second \\
filter membrane & $-\mathrm{Clean}$ the impurities: $3 \mathrm{~mL}$ & - Centrifuge the tubes at $2000 \mathrm{rpm}, 5$ \\
& $\mathrm{H}_{2} \mathrm{O}, 3 \mathrm{~mL} \mathrm{MeOH}$. & minutes. Transfer $1 \mathrm{~mL}$ of the \\
& $-\mathrm{Elution}: 4 \mathrm{~mL} \mathrm{MeOH:}$ & supernatant into vial. \\
& $\mathrm{NH}+\mathrm{OH}(95 / 5, \mathrm{v} / \mathrm{v})$. & - Inject sample into LC-MS/MS \\
\hline
\end{tabular}

\subsubsection{Mobile phase composition preparation}

Based on a number of references $[5,10,17]$ and the actual conditions of the laboratory, 05 mobile phase systems were selected of gradient separation, including:

- System 1: channel A: ACN, channel B: 2 mM ammonium acetate;

- System 2: channel A: MeOH, channel B: 2 mM ammonium acetate;

- System 3: channel A: ACN, channel B: $2 \mathrm{mM}$ ammonium formate;

- System 4: channel A: ACN, channel B: $2 \mathrm{mM}$ ammonium formate $+0.1 \%$ formic acid;

- System 5: channel A: ACN, channel B: $2 \mathrm{mM}$ ammonium acetate $+0.1 \%$ formic acid $/ \mathrm{H}_{2} \mathrm{O}$. 


\subsubsection{Method validation}

\subsubsection{Specificity}

The specificity of the method was evaluated by comparing the chromatograms of the analytes in the blank with standard and spiked samples. The specificity of the method was further guaranted by a confirmation method based on the IP (identification point) and ion ratio according to the regulations of the European Council. For LC-MS/MS, the method is specific when the IP score was 4.

\subsubsection{Linearity and calibration curves}

Prepared a mixed standard solution of sibutramine, N-desmethyl sibutramine and $\mathrm{N}$-didesmethyl sibutramine, diluted with appropriate ratio to obtain 06 concentrations: 2.0 $\mathrm{ng} / \mathrm{mL}, 5.0 \mathrm{ng} / \mathrm{mL}, 10 \mathrm{ng} / \mathrm{mL}, 20 \mathrm{ng} / \mathrm{mL}, 50 \mathrm{ng} / \mathrm{mL}$ and $100 \mathrm{ng} / \mathrm{mL}$, respectively. The calibration curve was constructed based on the relation between the concentration and the peak area of the corresponding standards. The calibration curve is linear when the correlation coefficient $\mathrm{R}^{2}$ was higher than 0.99 .

\subsubsection{Limit of detection (LOD) and limit of quantification (LOQ)}

LODs are the lowest SB, DSB, DDSB concentration in a sample that can be detected from the background noise but cannot be quantitated. LOD was determined when the signal - to noise ratio $(\mathrm{S} / \mathrm{N})$ of $3 / 1$ was reached. LOQ is defined as the lowest concentration of an analyte that can be determined with acceptable precision and accuracy. LOQ was determined as the concentration that provides the signal - to - noise ratio $(\mathrm{S} / \mathrm{N})$ of 10/1 [4].

\subsubsection{Recovery and repeatability}

The method repeatability and recovery were evaluated by measuring the spiked samples of hard capsule, soft capsule and teabag formulations at three concentration of $10 \mu \mathrm{g} / \mathrm{kg}, 20$ $\mu \mathrm{g} / \mathrm{kg}$ and $50 \mu \mathrm{g} / \mathrm{kg}$ with six replicates per concentration.

\subsubsection{Application to analysis of dietary supplement for weight loss}

The validated method was applied for analysis of real samples that were taken from Hanoi markets. Accurately weigh approx 1.0 gram of the sample into a falcon tube ( $50 \mathrm{~mL}$ capacity) and added $20 \mathrm{~mL}$ of suiltabe solvent, mix the contents thoroughly, ultrasound about 20 minutes, transfered the supernatant into a volumetric flask, 2 times repeatly. Adjusted the volume to 50 $\mathrm{mL}$, removed the impurities, and injected the sample on LC-MS/MS equipment.

\section{RESULTS AND DISCUSSION}

\subsection{Selection of mass spectrometry conditions}

Mass spectrometry analysis was performed in positive mode (ESI). The optimization in source parameters were as follows: curtain gas (CUR), 25 psi; ion spray voltage (IS), $5.500 \mathrm{~V}$; ion source gas 1 (GS 1), 20 psi; ion source gas 2 (GS 2), 20 psi; and temperature (TEM), $400^{\circ} \mathrm{C}$. The CAD (Collision-induced dissociation) gas was fixed at 9 psi. For optimal MS parameters, the highest intensity ion was used as quantitative ion and lower intensity ion were used as confirmation ion. The MS/MS conditional results for SB, DSB and DDSB analysis were presented in Table 2. 
Table 2. MS/MS conditions for qualitative and quantitative analysis of $S B, D S B, D D S B$

\begin{tabular}{lcccccc}
\hline Analyte & $\begin{array}{c}\text { Molecular } \\
\text { weight }\end{array}$ & $\begin{array}{c}\text { Retention } \\
\text { time (min) }\end{array}$ & $\begin{array}{c}\text { Precursor } \\
\text { ion }(\boldsymbol{m} / \mathbf{z})\end{array}$ & $\begin{array}{c}\text { Product } \\
\text { ion }(\boldsymbol{m} / \mathbf{z})\end{array}$ & $\begin{array}{c}\text { Collision } \\
\text { energy (V) }\end{array}$ & $\begin{array}{c}\text { Collision Cell Exit } \\
\text { Potential (V) }\end{array}$ \\
\hline SB & 278.9 & 6.37 & 279.9 & 124.8 & 22 & 26 \\
& & & & 138.4 & 16 & 26 \\
DSB & 265.0 & 6.33 & 266.0 & 124.8 & 24 & 28 \\
& & & & 138.8 & 12 & 28 \\
DDSB & 251.1 & 6.27 & 252.1 & 208.1 & 47 & 11 \\
& & & & 268.2 & 47 & 11 \\
\hline
\end{tabular}

\subsection{Investigation of extraction solvent}

Sibutramine, N-desmethyl sibutramine and N-didesmethyl sibutramine were spiked to 03 matrices including hard capsules, soft capsules and teabags. After being extracted with different solvents, the recoveries of SB, DSB and DDSB were shown in Table 3.

Table 3. Recoveries of $S B, D S B$ and DDSB using different extraction solvents

\begin{tabular}{lccccccccc}
\hline \multirow{2}{*}{ Solvents } & \multicolumn{3}{c}{ Hard capsule } & \multicolumn{3}{c}{ Soft capsule } & \multicolumn{3}{c}{ Teabag } \\
& SB & DSB & DDSB & SB & DSB & DDSB & SB & DSB & DDSB \\
\hline $\mathrm{MeOH}$ & 110.6 & 102.1 & 105.2 & 99.3 & 98.7 & 109.1 & 98.8 & 104.1 & 97.2 \\
$\mathrm{ACN}$ & 97.6 & 97.8 & 89.2 & 93.4 & 92.1 & 85.3 & 95.1 & 94.4 & 83.5 \\
$\mathrm{EtOH}$ & 84.2 & 87.8 & 85.1 & 95.2 & 85.3 & 83.2 & 82.1 & 84.5 & 79.2 \\
Acetone & 78.3 & 81.9 & 75.4 & 81.3 & 71.6 & 75.4 & 81.5 & 78.7 & 89.8 \\
\hline
\end{tabular}

Comparing the content of analytes obtained from the use of different extraction solvents in different matrices (Table 3), methanol $(\mathrm{MeOH})$ is the extraction solvent that provides the highest extraction efficiency. Therefore, $\mathrm{MeOH}$ was the solvent of choice in the study.

\subsection{Selection of cleanup steps}

The recovery efficiencies of blank samples spiked with standards: sibutramine, $\mathrm{N}$-desmethyl sibutramine and $\mathrm{N}$-didesmethyl sibutramine after being cleaned by different cleaning techniques are presented in Table 4.

Table 4. Recovery efficiencies of $S B, D S B, D D S B$ using different procedures

\begin{tabular}{lccc}
\hline & \multicolumn{3}{c}{ Recovery efficiency (\%) } \\
\cline { 2 - 4 } Procedure & Sibutramine & $\begin{array}{c}\text { N-desmethyl } \\
\text { sibutramine }\end{array}$ & $\begin{array}{c}\text { N-didesmethyl } \\
\text { sibutramine }\end{array}$ \\
\hline Procedure 1 & 90.7 & 93.7 & 85.0 \\
Procedure 2 & 93.9 & 98.7 & 91.5 \\
Procedure 3 & 94.8 & 107.0 & 100.0 \\
\hline
\end{tabular}

Food supplements are usually prepared from herbs, so the post-extracted solution is often chromatic. The extract was passed through filter paper and a solid-phase extraction column, but the color of the solution still remains Using GCB decreased the color of extract solution which 
is the reason for the higher recovery efficiency compared with using solid phase extraction column and the membrane filtration method. This is explained that activated carbon is capable of adsorbing pigments and commonly used on the laboratory scale to purify solutions containing unwanted colored organic impurities.

\subsection{Optimization of the amount of graphitized carbon black (GCB)}

Graphitized carbon black has ability to adsorb color of solution, but using too much or too little of activated carbon also leads to a change in the recovery efficiency of the analyte. The results on the influence of activated carbon amount on the recovery efficiency were shown in Figure 1.

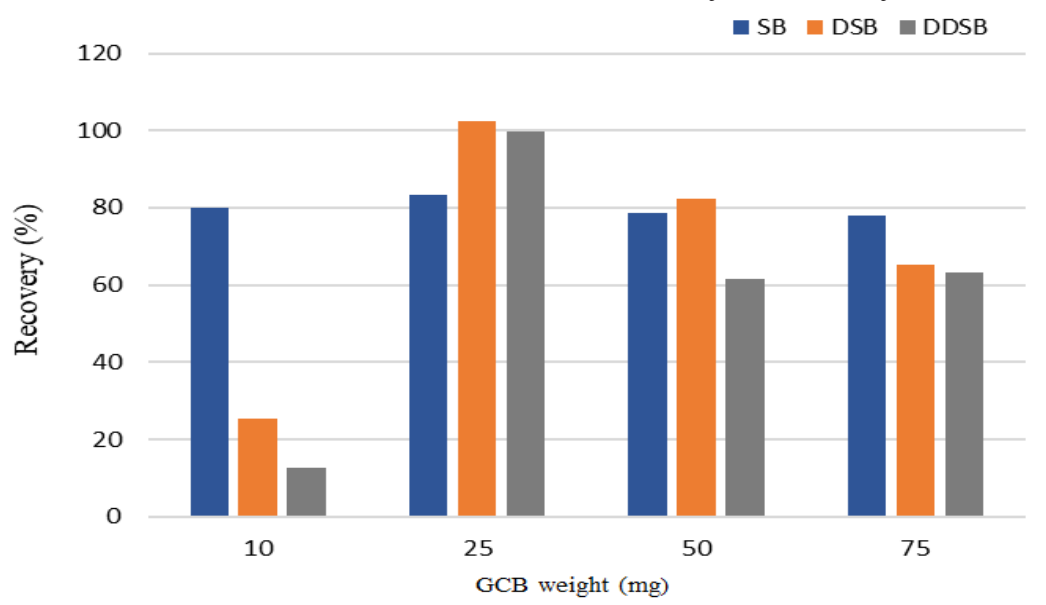

Figure 1. Effects of the amount of $G C B$ on recovery of $S B, D S B, D D S B$ (teabag matrix)

As can be seen in figure 1, using $25 \mathrm{mg}$ of GCB for $10 \mathrm{~mL}$ of sample solution gave the highest recovery efficiency of the analytes in teabag sample. $10 \mathrm{mg}$ of GCB was not enough to adsorb all impurities, so the recovery efficiency was lowest, when the amount of GCB increased, the recovery efficiency decreased. GCB was coal with an extremely large surface area per unit volume and it is a network of pores under the membrane where absorption took place. With 50 and $75 \mathrm{mg}$ of GCB, the recoveries of SB, DSB and DDSB were lower, these are explained possible because GCB may adsorb both impurities and analytes.

\subsection{Mobile phase composition}

Mobile phase affected the ability to separate analytes in the mixture, different mobile phases give differen signals for analytes, mobile phase programs of 5 systems were similar. The dependence of peak area of sibutramine, N-desmethyl sibutramine and N-didesmethyl sibutramine on different mobile phases is presented in Table 5. System 1 to system 5 was detailed in 2.4.1.3.

Table 5. Influence of mobile phase components

\begin{tabular}{lcccccc}
\hline \multirow{2}{*}{$\begin{array}{l}\text { Mobile phase } \\
\text { system }\end{array}$} & \multicolumn{2}{c}{ Sibutramine } & \multicolumn{2}{c}{$\begin{array}{c}\text { N-desmethyl } \\
\text { sibutramine }\end{array}$} & \multicolumn{2}{c}{$\begin{array}{c}\text { N-didesmethyl } \\
\text { sibutramine }\end{array}$} \\
\cline { 2 - 7 } & Peak area & $\boldsymbol{R} \boldsymbol{T}^{(*)}$ & Peak area & $\boldsymbol{R} \boldsymbol{T}^{(*)}$ & Peak area & $\boldsymbol{R T}^{(*)}$ \\
\hline System 1 & $5.17 \times 10^{5}$ & 6.50 & $6.94 \times 10^{5}$ & 6.39 & $4.21 \times 10^{5}$ & 6.35 \\
System 2 & $5.01 \times 10^{5}$ & 8.55 & $6.54 \times 10^{5}$ & 6.65 & $3.89 \times 10^{5}$ & 6.67 \\
System 3 & $8.25 \times 10^{5}$ & 6.45 & $9.01 \times 10^{5}$ & 6.40 & $4.72 \times 10^{5}$ & 6.34 \\
System 4 & $6.29 \times 10^{5}$ & 7.11 & $6.78 \times 10^{5}$ & 7.16 & $3.11 \times 10^{5}$ & 7.18 \\
System 5 & $9.09 \times 10^{5}$ & 6.29 & $1.25 \times 10^{5}$ & 6.27 & $9.61 \times 10^{5}$ & 6.23 \\
\hline
\end{tabular}


Mobile phase system 5 is the gradient of channel A: ACN, channel B: $2 \mathrm{mM}$ ammonium acetate $+0.1 \%$ formic acid $/ \mathrm{H}_{2} \mathrm{O}$ provided the highest peak area of sibutramine, $\mathrm{N}$-desmethyl sibutramine and $\mathrm{N}$-didesmethyl sibutramine. Using this mobile phase with gradient program in Table 6, we obtained the chromatogram of SB, DSB and DDSB as presented in Fig. 2.

Table 6. Gradient program

\begin{tabular}{ccc}
\hline Time (min) & $\mathbf{\% A}$ & $\mathbf{\% B}$ \\
\hline 0.01 & 100 & 0 \\
3 & 90 & 10 \\
5 & 5 & 95 \\
7 & 5 & 95 \\
8 & 90 & 10 \\
10 & 90 & 10 \\
\hline
\end{tabular}

\subsection{Method validation}

\subsubsection{Specificity}

Analysis of blank samples, standard samples and blank samples were spiked with standards at $5 \mathrm{ng} / \mathrm{mL}$ to all 3 matrices including hard capsules, teabags and soft capsules. An example of chromatograms of SB are shown in Figure 3.

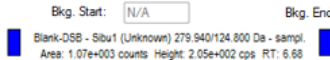

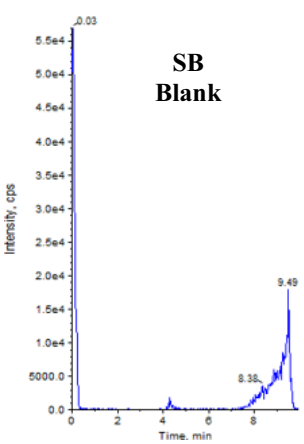

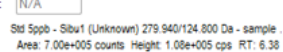

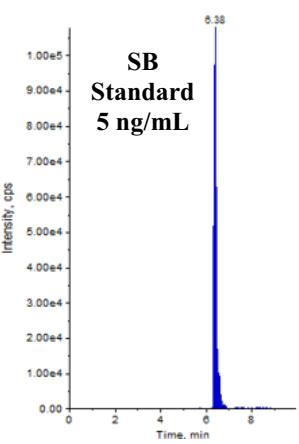

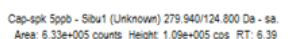

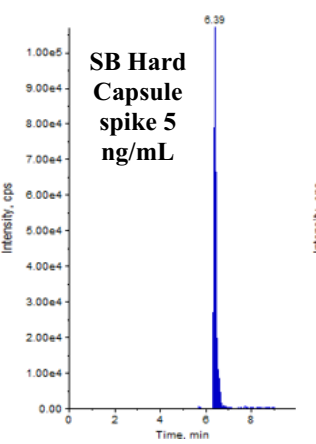

(a)

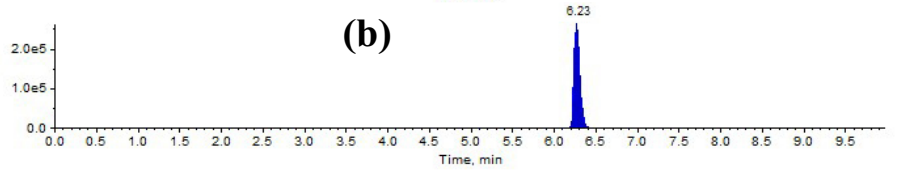

(c)

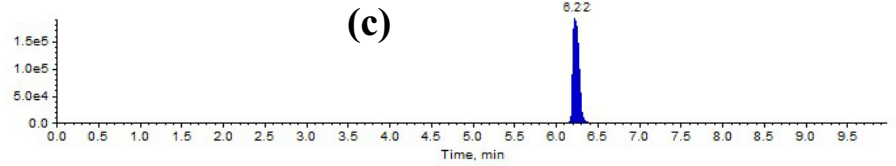

Figure 2. Chromatogram of $S B(a), D S B(b), D D S B$ (c) in optimal mobile phase and gradient condition

Figure 3. Chromatograms of blank sample, standard solution and spiked blank samples for $S B$

On the chromatograms, the blank samples did not show the signal of the SB, while the blank spiked with standards have peaks of sibutramine with retention time similar to that of corresponding standard. This confirmed that the method was specific.

Table 2 showed that each SB, DSB and DDSB precusor ions were bombarded into 2 daughter ions, so the total number of identification points of the method corresponding to each substance was 4 conformable with the regulation 2002/657/EC of the European Council, which confirmed the LC-MS/MS method in this study was specific.

\subsubsection{Linearity and calibration curves}

The standard solution of SB, DSB and DDSB from $2 \mathrm{ng} / \mathrm{mL}$ to $100 \mathrm{ng} / \mathrm{mL}$ was analyzed to determine the linearity. Calibration equations, correlation coefficients and bias of SB, DSB 
and DDSB in this range were shown in Table 7.

Table 7. Calibration equations and correlation coefficients of SB, DSB and DDSB

\begin{tabular}{lccc}
\hline Analytes & Calibration equations & $\begin{array}{c}\text { Correlation } \\
\left.\text { coefficients ( } \boldsymbol{R}^{2}\right)\end{array}$ & Bias (\%) \\
\hline Sibutramine & $\mathrm{y}=5.08 \times 10^{4} \mathrm{x}-5.35 \times 10^{3}$ & 0.9982 & $4.52-12.1$ \\
N-desmethyl sibutramine & $\mathrm{y}=6.41 \times 10^{4} \mathrm{x}-7.18 \times 10^{4}$ & 0.9996 & $3.81-10.7$ \\
N-didesmethyl sibutramine & $\mathrm{y}=3.69 \times 10^{4} \mathrm{x}-6.12 \times 10^{4}$ & 0.9984 & $2.52-9.83$ \\
\hline
\end{tabular}

As can be seen from Table 7, correlation coefficients of three calibrations were higher than 0.990 , bias was smaller than 15\%, which met the criteria of AOAC requirements and proved the high linearity between the peak area and concentration of analyte.

Figure 4 is an example of SB calibration curve.

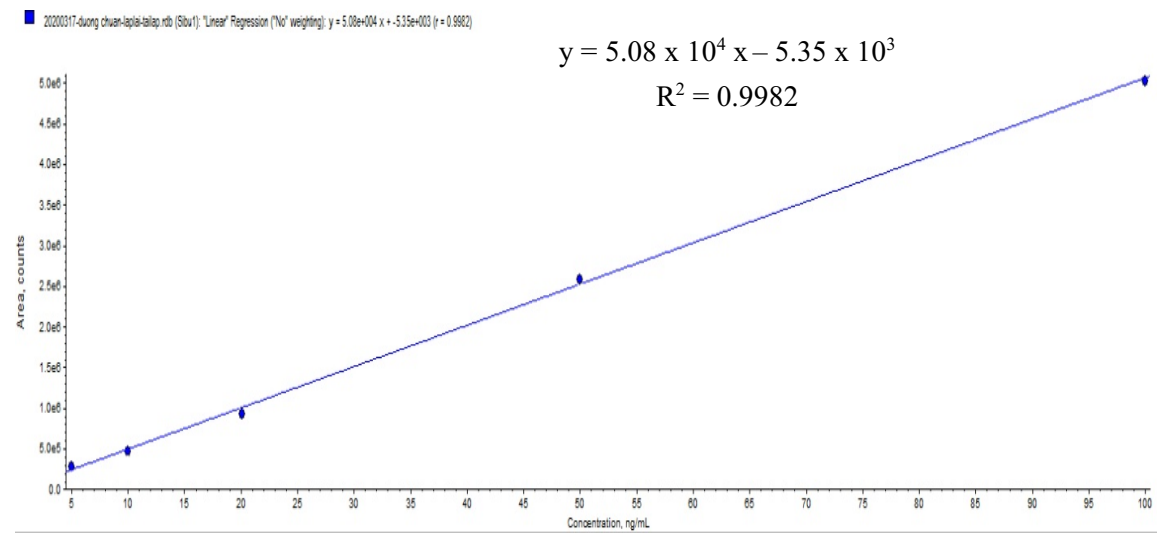

Figure 4. Calibration curve of $S B$

3.6.3. Limit of detection (LOD) and limit of quatification (LOQ)

After optimizing analytical conditions for determination of SB and its derivative on LC-MS/MS equipment, the limit of detection (LOD) and limit of quantification (LOQ) of SB, DSB and DDSB were determined. Results were presented in Table 8.

Table 8. Limit of detection (LOD) and limit of quantification (LOQ) of the analytes

\begin{tabular}{lcc}
\hline Analytes & LOD $(\boldsymbol{\mu g} / \mathbf{k g})$ & $\boldsymbol{L O Q}(\boldsymbol{\mu g} / \mathbf{k g})$ \\
\hline Sibutramine & 0.05 & 0.15 \\
N-desmethyl sibutramine & 0.10 & 0.30 \\
N-didesmethyl sibutramine & 0.10 & 0.30
\end{tabular}

The method's LOQs of SB, DSB and DDSB at $0.15,0.3,0.3 \mu \mathrm{g} / \mathrm{kg}$, respectively confirmed that it has sensitivity enough to analyze the dietary supplement for food control samples on the market.

\subsubsection{Recovery and repeatability}

The recovery and repeatability of the method were assessed by analyzing spiked samples at three different concentration levels of $10,20,50 \mu \mathrm{g} / \mathrm{kg}$ with six replicates at each concentration. The results were shown in Table 9. 
Table 9. Recovery ( $R \%$ ) and repeatability (RSD \%) of SB, DSB and DDSB at three concentration in different matrices

\begin{tabular}{|c|c|c|c|c|c|c|c|}
\hline \multirow{2}{*}{ Dosage form } & \multirow{2}{*}{ Analytes } & \multicolumn{2}{|c|}{$10 \mu g / k g, n=6$} & \multicolumn{2}{|c|}{$20 \mu \mathrm{g} / \mathrm{kg}, \mathrm{n}=6$} & \multicolumn{2}{|c|}{$50 \mu \mathrm{g} / \mathrm{kg}, \mathrm{n}=6$} \\
\hline & & $R(\%)$ & $R S D(\%)$ & $R(\%)$ & $R S D(\%)$ & $R(\%)$ & $R S D(\%)$ \\
\hline \multirow[t]{3}{*}{ Hard capsule } & SB & 90.6 & 8.90 & 99.0 & 6.42 & 100.1 & 6.32 \\
\hline & DSB & 92.7 & 7.30 & 107.3 & 5.25 & 101.6 & 4.98 \\
\hline & DDSB & 100.1 & 4.52 & 84.9 & 5.01 & 94.7 & 3.75 \\
\hline \multirow[t]{3}{*}{ Soft capsule } & SB & 100.4 & 6.32 & 100.5 & 5.85 & 105.7 & 5.01 \\
\hline & DSB & 100.5 & 10.5 & 100.5 & 7.85 & 107.0 & 7.01 \\
\hline & DDSB & 102.6 & 8.34 & 104.1 & 7.56 & 105.0 & 4.85 \\
\hline \multirow[t]{3}{*}{ Teabag } & SB & 100.5 & 5.34 & 109.5 & 8.72 & 100.5 & 6.09 \\
\hline & DSB & 109.0 & 4.78 & 87.7 & 7.34 & 93.6 & 4.01 \\
\hline & DDSB & 101.8 & 6.03 & 108.3 & 5.85 & 102.3 & 4.79 \\
\hline
\end{tabular}

The recoveries of SB, DSB and DDSB of three dosage forms at three different concentrations were found in the range of $90.6-109.5 \%, 92.7-109.0 \%$ and $84.9-108.3 \%$, respectively. Standard deviation (RSD \%) were found in the range of $5.01-8.90 \%, 4.01-10.5 \%, 3.75$ $8.34 \%$, respectively. The recoveries and RSD meet the requirements of AOAC (recovery of 80 - $100 \%$, relative standard deviation $\leq 15 \%$ at $10 \mu \mathrm{g} / \mathrm{kg}$ concentration).

\subsection{Application for analysis of real samples}

The validated method was used successfully to quantify SB, DSB and DDSB in 30 weight loss dietary supplements samples taken from some pharmacies in Hanoi. 04 samples of hard capsule and 02 samples of soft capsule were detected to contain sibutramine with contents between 0.817 - $31.4 \mathrm{mg} / \mathrm{g}, 02$ samples of hard capsule, 02 samples of soft capsules contain $\mathrm{N}$-desmethyl sibutramine with contents in the range of $0.27-3.10 \mathrm{mg} / \mathrm{g}$. There was no sample detected with N-didesmethyl sibutramine.

\section{CONCLUSIONS}

In this study, an analytical method using LC-MS/MS for simultaneous determination of SB, DSB and DDSB in weight loss dietary supplement was developed and fully validated. All the parameters meet the acceptance criteria for method validation according to the AOAC. The method showed good specificity and linearity. The developed method is rapid, sensitive and can be used to quantify SB and its derivative as well as can be transfered to laboratories equipped with mass spectrometry liquid chromatography equipment. The method helps to alert the authorities of the quality of weight loss dietary supplements.

\section{REFFERENCES}

[1] A. Krivohlavek, I. Žuntar, M. Ivešić, I. M. Andačić, S. Šikić, and M. Vrebčević, "Sibutramine in slimming food supplements on the Croatian market determined by validated high-pressure liquid chromatographyelectrospray tandem mass spectrometry method", Journal of Food and Nutrition Research, vol. 55, pp. 222-228, 2016.

[2] E. P. Gueorguieva, K. Ivanov, S. Gueorguiev, A. Mihaylova, V. Madzharov and S. Ivanova, "Detection of sibutramine in herbal food supplements by UHPLC/HRMS and UHPLC/MS-MS", 
Biomedical Research, vol. 29, no. 14, pp. 3006-3009, 2018

[3] H. M. Yano, F. F. Farias, M. B. D. Bianco and L. M. Trujllo, "Determination of the Sibutramine Content of Dietary Supplements Using LC-ESI-MS/MS”, Journal of Pharmaceutical Analysis. 32 (8): 1164-1169, 2013.

[4] V. S. Ponnuru, B.R. Challa and R. Nadendla, "Quantification of sibutramine and its two metabolites in human plasma by LC-ESI - MS/MS and its application in a bioequivalence study", Journal of Pharmaceutical Analysis, vol. 2, no. 4, pp. 249-257, 2012.

[5] P. Zou, S. S-Y. Oh, K.-H. Kiang, M-Y. Low and B.C. Bloodworth, "Detection of sibutramine, its two metabolites and one analogue in a herbal product for weight loss by liquid chromatography triple quadrupole mass spectrometry and time-of-flight mass spectrometry", Rapid Communications in Mass Spectrometry, vol. 21, no. 4, pp. 614-618, 2007.

[6] J. Wang, B. Chen and S. Yao, "Analysis of six synthetic adulterants in herbal weight-reducing dietary supplements by LC electrospray ionization-MS", Food Additives \& Contaminants: Part A, vol. 25, no. 7, pp. 822-830, 2008.

[7] J. Chen, W. Lu, Q. Zhang and X. Jiang, "Determination of the active metabolite of sibutramine by liquid chromatography-electrospray ionization tandem mass spectrometry", Journal of Chromatography B, vol. 785, pp. 197-203, 2003.

[8] S. H. Roh, Y.P. Kang, S. Park, Y. Huh, J. Lee, J.H. Park, D. Kim and S.W. Kwon, "Determination of tadalafil and N-desmethylsibutramine in health and dietary supplements using ultraperformance liquid chromatography (UPLC) coupled with quadrupole-time-of-flight mass spectrometry (QTOF MS)", Food Additives and Contaminants, vol. 28, no. 11, pp. 1475-1482, 2011.

[9] E. Ariburnu, M. F. Uludag, H. Yalcinkaya and E. Yesilada, "Comparative determination of sibutramine as an adulterant in natural slimming product by HPLC and HPTLC densitometry”, Journal of Pharmaceutical and Biomedical Analysis, vol. 64-65, pp. 77-81, 2012.

[10] Z. Huang, S. Xiao, D. Luo, Bo Chen and S. Yao, "Simultaneous Determination of Sibutramine and N-Di-desmethylsibutramine in Dietary Supplements for Weight Control by HPLC-ESI-MS", Journal of Chromatographic Science, vol. 46, no. 8, pp. 707-711, 2008.

[11] M. Chorilli, R. Bonfilio, R. S. Chicarelli and H. R. N. Salgado, "Development and validation of an analytical method by PR-HPLC for quantification of sibutramine in pharmaceutical capsule", Analytical Methods, vol. 3, pp. 985-990, 2011.

[12] Y. Chena, L. Zhaob, F. Lua, Y. Yuc, Y. Chaia and Y. Wua, "Determination of synthetic drugs used to adulterate botanical dietary supplements using QTRAP LC-MS/MS", Food Additives and Contaminants, vol. 26, no. 5, pp. 595-603, 2009.

[13] F. V. Sardela, M. T. R. Motta, M. C. Padilha, H. M. G. Pereira and F. R. Aquino Neto, "Analysis of sibutramine metabolites as Ntrifluoroacetamide and O-trimethylsilyl derivatives by gas chromatography-mass spectrometry in urine”, Journal of Chromatogr B, vol. 877, no. 27, pp. 3003-3011, 2009.

[14] S. Strano-Rossi, C. Colamonici and F. Botre, "Detection of sibutramine administration: a gas chromatography/mass spectrometry study of the main urinary metabolites", Rapid Communication in Mass Spectrometrometry, vol. 21, no. 2, pp. 79-88, 2007.

[15] P. Zou, S. S-Y. Oh, K-H. Kiang, M-Y. Low and B. C. Bloodword, "Detection of sibutramine, 
its two metabolites and one analogue in a herbal product for weight loss by liquid chromatography triple quadrupole mass spectrometry and time-of-flight mass spectrometry", Rapid Communication in Mass Spectrometrometry, vol. 21, pp. 614-618, 2007.

[16] N. T. Luyện, "Xác định chất cấm Sibutramine trong thực phẩm chức năng giảm béo bằng phương pháp HPLC", Luận văn Thạc sỹ, Đại học Quốc gia Hà Nội, Việt Nam, 2014.

[17] T. Kamadi, I. Fidrianny, Amirmusadad, "Development of analytical method for identification of sibutramine in traditional medicine using solid phase extraction: high performance liquid chromatography", Asian Journal of Pharmaceutical and Clinical Research, vol 9, no. 6, pp. 201-209, 2016.

\section{Xác định đổng thời hàm lượng sibutramine và một số dẫn xuất trong thực phẩm bổ sung hỗ trợ giảm cân bằng sắc ký lỏng khối phổ hai lẩn (LC-MS/MS)}

Dương Thị Mai Hoa ${ }^{1,2}$, Phạm Thị Ngọc Mai ${ }^{2}$ Hoàng Quốc Anh ${ }^{2}$ Cao Công Khánh ${ }^{1}$, Nguyễn Thị Hồng Ngọc ${ }^{1}$ Mạc Thị Thanh Hoa ${ }^{1}$ Trần Hùng Sơn ${ }^{1}$, Nguyễn Thị Vân $\mathrm{Anh}^{3}$, Lê Thị Hồng Hảo ${ }^{1,2}$

${ }^{1}$ Viện Kiểm nghiệm an toàn vệ sinh thực phẩm quốc gia ${ }^{2}$ Truoòng Đại học khoa học Tự nhiên - Đại học quốc gia Hà Nội ${ }^{3} H o c$ viện Y Dược hoc cổ truyền Việt Nam

Tóm tắt

Phương pháp sắc ký lỏng khối phổ hai lần được sử dụng để xác định hàm lượng của sibutramine $(\mathrm{SB}), \mathrm{N}$-desmethyl sibutramine (DSB) và N-didesmethyl sibutramine (DDSB), là những chất trộn trái phép trong thực phẩm bổ sung hỗ trợ giảm cân. Sibutramine và dẫn xuất của nó được chiết bởi dung môi methanol, sau đó tạp chất được loại bằng carbon hoạt tính (GCB). Quá trình tách sắc ký được thực hiện trên cột sắc ký C18 $(100 \mathrm{~mm}$ x 2,1mm, 3,5 $\mu \mathrm{m})$. Pha động là gradient của 2 kênh: Kênh $\mathrm{A}$ là Acetonitril, kênh $\mathrm{B}$ là hỗn hợp ammoni acetate 2 $\mathrm{mM}+$ acid formic $0,1 \%$. Kỹ thuật ghi phổ MRM ở chế ion dương được sử dụng để phát hiện $\mathrm{SB}, \mathrm{DSB}$ và $\mathrm{DDSB}$ với số khối tương ứng $\mathrm{m} / \mathrm{z}$ là $279,9 / 124,8 ; 266,0 / 124,8$ và $252,1 / 125,0$. Phương pháp đã được thẩm định và đáp ứng yêu cầu của $A O A C$ về độ đặc hiệu, độ tái lặp và độ thu hồi. Đường chuẩn được xây dựng tuyến tính trong khoảng $0,002-0,100 \mu \mathrm{g} / \mathrm{mL}$ đối với $\mathrm{SB}, \mathrm{DSB}$ và $\mathrm{DDSB}$, hệ số tương quan lớn hơn 0,990 . Phương pháp đã được ứng dụng để xác định hàm lượng $\mathrm{SB}, \mathrm{DSB}$ và $\mathrm{DDSB}$ trong thực phẩm bổ sung hỗ trợ giảm cân, mẫu được lấy ngẫu nhiên tại các cửa hàng thuốc trên địa bàn Hà Nội ở cả 3 dạng viên nang cứng, viên nang mềm và trà túi lọc. Kết quả phát hiện sáu mẫu chứa $\mathrm{SB}$, và $\mathrm{DSB}$ có hàm lượng nằm trong khoảng $0,817-31,7 \mathrm{mg} / \mathrm{g}$.

Tù̀ khóa: sibutramine, $N$-desmethyl sibutramine, $N$-didesmethyl sibutramine, thục phẩm bổ sung, giảm cân, $L C-M S / M S$. 